\title{
Patterns of Alcohol Consumption and Suicidal Behavior: Findings From the Fourth and Fifth Korea National Health and Nutritional Examination Survey (2007-2011)
}

\author{
Hong-Chul Bae ${ }^{1,2}$, Seri Hong ${ }^{3}$, Sung-In Jang ${ }^{1,2}$, Kwang-Sig Lee ${ }^{1,2}$, Eun-Cheol Park ${ }^{1,2}$ \\ ${ }^{1}$ Department of Preventive Medicine, Yonsei University College of Medicine, Seoul; ${ }^{2}$ Institute of Health Services Research, Yonsei University College of \\ Medicine, Seoul; ${ }^{3}$ Department of Preventive Medicine, Graduate School of Public Health, Yonsei University, Seoul, Korea
}

Objectives: The purpose of this study was to investigate the association between suicidal behavior and patterns of alcohol consumption in Korean adults.

Methods: This study was based on data provided by the Korea National Health and Nutritional Examination Survey from 2007 to 2011. A total of 42347 subjects were included in the study, of whom 19292 were male and 23055 were female. Logistic regression analysis was performed to assess the association between patterns of alcohol consumption and suicidal behavior.

Results: Among the study subjects, 1426 males (11.3\%) and 3599 females (21.2\%) had experienced suicidal ideation, and 106 males (0.8\%) and 190 females (1.1\%) had attempted suicide during the previous 12 months. Alcohol Use Disorders Identification Test (AUDIT) scores were found to be associated with suicidal ideation in males and associated with both suicidal ideation and suicide attempts in females. Alcoholic blackouts were associated with suicidal ideation and suicide attempts in males, and were also associated with suicidal ideation in females.

Conclusions: In this study, we found that certain patterns of alcohol consumption were associated with suicidal behaviors. In particular, only alcoholic blackouts and categorized AUDIT scores were found to be associated with suicidal behavior in males. We therefore suggest that further research is needed to examine this relationship prospectively and in other settings.

Key words: Alcohol consumption, Suicidal ideation, Suicide, Attempted

\section{INTRODUCTION}

Suicide is a common cause of death in most developed countries. In Korea, it was the fourth leading cause of death (28.1 per 100 000) in 2012 [1]. Additionally, Korea is ranked first among

Received: June 30, 2014 Accepted: April 27, 2015

Corresponding author: Eun-Cheol Park, MD, PhD

50-1 Yonsei-ro, Seodaemun-gu, Seoul 120-752, Korea

Tel: +82-2-2228-1862, Fax: +82-2-392-8133

E-mail: ecpark@yuhs.ac

This is an Open Access article distributed under the terms of the Creative Commons Attribution Non-Commercial License (http://creativecommons.org/licenses/bync/3.0/) which permits unrestricted non-commercial use, distribution, and reproduction in any medium, provided the original work is properly cited. the Organization for Economic Cooperation and Development (OECD) countries in suicide mortality [2]. Suicidal ideation and suicidal behavior, such as prior suicide attempts, are strong indicators of suicide, but only a minority of those attempting suicide seek medical attention from health care facilities [3-6], while the majority of unsuccessful attempts go unnoticed [7].

Alcohol is one of the leading causes of the global burden of disease [8], and alcohol use disorders are known to be a major risk factor for suicide [9]. Individuals with an alcohol use disorder are at high risk for multiple suicide attempts $[10,11]$. The risk of suicidal behavior, such as suicide attempts and completed suicide, in alcohol-dependent individuals is epidemiologically and clinically significant [12]. 
The Alcohol Use Disorders Identification Test (AUDIT) is one of the most frequently used tools in the world for assessing drinking problems in individual patients. The AUDIT score is calculated by summing the scores of 10 questionnaires about alcohol consumption, including questions about frequency of consumption and the amount of alcohol consumed per occasion. The total score is between 0 and 40; a score of 0 to 7 is considered to reflect low risk of alcohol dependence, while a score of 8 to 15 reflects medium risk of alcohol dependence, a score of 16 to 19 corresponds to high risk of alcohol dependence, and a score of 20 to 40 reflects alcohol dependence [13]. Alcoholic blackout refers to amnesia involving the events of any part of a drinking episode, without loss of consciousness, and can occur during alcohol intoxication in individuals with or without an alcohol use disorder [14]. AUDIT scores and alcoholic blackouts are associated with alcohol use disorders, which are, in turn, associated with suicide [15], but the relationship between alcohol use and suicidal behavior in the general population has not been well established.

Various studies have been conducted to evaluate possible associations between alcohol consumption and suicidal ideation or suicide attempts. However, most studies have examined associations involving the frequency of alcohol consumption, the amount of alcohol consumed, and the frequency of binge drinking $[16,17]$. Therefore, in this study using data from nationwide surveys, we investigated the association between patterns of alcohol consumption, including alcoholic blackouts, and suicidal behavior in Korean adults.

\section{METHODS}

\section{Study Design and Participants}

This study was based on data from the fourth and fifth Korea National Health and Nutritional Examination Survey (KNHANES) from 2007 to 2011. The KNHANES consisted of three components: a health interview survey, a nutrition survey, and a health examination survey. A total of 42347 subjects were included.

We used data from the health interview for this study. Items pertaining to socioeconomic status, the presence of diseases, the assessment of medical services, and nutrition were presented by trained interviewers and items related to health behavior, including smoking status, alcohol consumption, and mental health were based on self-reported questionnaires. All participants provided written informed consent to participate in the survey, which was approved by the institutional review board of the Korea Centers for Disease Control and Prevention [18].

\section{Measurement of Variables}

We used the AUDIT score to assess patterns of alcohol use. The frequency of alcohol consumption during the previous year was categorized as follows: never during the last year, less than monthly, monthly, two to four times a month, two to three times a week, more than four times a week, and nondrinking. In this analysis, respondents who reported not drinking during the previous year were considered to be non-drinking. The quantity of alcohol consumption per occasion during the previous year was categorized as follows: one to two drinks, three to four drinks, five to six drinks, seven to nine drinks, more than ten drinks, and non-drinking. The frequency of alcoholic blackouts during the previous year was categorized as follows: never, less than monthly, monthly, weekly, almost daily, and non-drinking. We regarded non-drinking respondents as falling into the category of "never," and combined the weekly and almost daily categories because of the small number of female responders in these categories. We divided the AUDIT scores into four categories in order to facilitate comparison: 0 to 7, 8 to 15,16 to 19 , and 20 to 40 [13]. People with suicidal ideation were defined as those who had experienced suicidal ideation during the previous 12 months, and suicide attempters were defined as those who had attempted suicide during the previous 12 months. Several factors affected the prevalence of suicidal ideation and suicide attempts, such as age, educational level, household income level, region, employment status, living alone, private insurance, smoking status, and history of major depression during the previous 12 months.

\section{Statistical Analysis}

Characteristics of the study population relating to suicidal ideation and suicide attempts were compared using the chisquared test for categorical variables and the Student's $t$-test for continuous variables. In order to assess the association between alcohol use and suicide attempts, logistic regression analysis was performed to determine odds ratios (ORs) and 95\% confidence intervals ( $\mathrm{Cls}$ ). In order to compare the influence of the AUDIT categories on suicidal ideation and suicide attempts to that of the frequency or quantity of drinking and the frequency of alcoholic blackouts, the independent variable was switched from the categorized AUDIT score to the other parameters, without any change in the confounders. Thus, four models were generated: categorized AUDIT scores, drinking 
frequency, drinking quantity, and frequency of alcoholic blackouts. A $p$-value $<0.05$ was considered statistically significant. Statistical analysis was performed using SAS version 9.2 (SAS Institute Inc., Cary, NC, USA).

Table 1. General characteristics and alcohol consumption patterns of study subjects by sex

\begin{tabular}{|c|c|c|c|}
\hline & $\begin{array}{c}\text { Males } \\
(n=19292)\end{array}$ & $\begin{array}{c}\text { Females } \\
(n=23055)\end{array}$ & $p$-value \\
\hline Age (y) & & & $<0.001$ \\
\hline$<40$ & $9344(56.4)$ & $10422(52.4)$ & \\
\hline $40-64$ & 5853 (34.9) & 7558 (34.8) & \\
\hline$\geq 65$ & $2866(8.7)$ & 4020 (12.8) & \\
\hline No. of household members & & & $<0.001$ \\
\hline $1-2$ & 4047 (18.7) & $5611(20.5)$ & \\
\hline 3 & $3923(23.9)$ & $4570(22.2)$ & \\
\hline 4 & $6582(38.0)$ & $7254(35.2)$ & \\
\hline$\geq 5$ & 3468 (19.4) & $4522(22.1)$ & \\
\hline Education level & & & $<0.001$ \\
\hline$\leq$ Elementary school & $6885(27.7)$ & $9824(37.2)$ & \\
\hline Middle school & $2235(12.6)$ & $2375(12.2)$ & \\
\hline High school & 4651 (32.9) & $5523(29.7)$ & \\
\hline$\geq$ College & $4050(26.8)$ & 4015 (20.9) & \\
\hline Household income level & & & $<0.001$ \\
\hline Low & $2925(14.1)$ & 4203 (16.8) & \\
\hline Mid-low & $4551(26.2)$ & $5554(27.0)$ & \\
\hline Mid-high & $5188(30.1)$ & $6086(29.2)$ & \\
\hline High & 5072 (29.6) & $5701(27.0)$ & \\
\hline Region & & & 0.14 \\
\hline Megalopolis' & $3274(21.1)$ & $4001(21.9)$ & \\
\hline Metropolitan² & $4643(25.3)$ & 5778 (25.3) & \\
\hline Others & $10146(53.6)$ & $12221(52.9)$ & \\
\hline Employment state & & & $<0.001$ \\
\hline Employed & 9348 (76.4) & 7932 (51.0) & \\
\hline Unemployed & $3582(23.6)$ & $8726(49.0)$ & \\
\hline Lives with spouse & & & $<0.001$ \\
\hline Yes & 9957 (59.4) & 11710 (56.9) & \\
\hline No & $6655(40.6)$ & $8933(43.1)$ & \\
\hline Private insurance & & & 0.17 \\
\hline Yes & 12732 (74.7) & $15424(74.0)$ & \\
\hline No & 4935 (25.3) & $6,155(26.0)$ & \\
\hline Smoking status & & & $<0.001$ \\
\hline Non & 5709 (31.3) & 18066 (88.2) & \\
\hline Ex-smoker & 2111 (11.4) & 405 (2.4) & \\
\hline Current smoker & 8172 (57.3) & $1596(9.4)$ & \\
\hline
\end{tabular}

(Continued to the next)

\section{RESULTS}

The general characteristics and alcohol consumption patterns of the study subjects are shown in Table 1. Of the 42347 study subjects, 19292 participants were male and 23055 were female. Statistically significant differences were found between

Table 1. Continued

\begin{tabular}{|c|c|c|c|}
\hline & $\begin{array}{c}\text { Males } \\
(n=19292)\end{array}$ & $\begin{array}{l}\text { Females } \\
(n=23055)\end{array}$ & $p$-value \\
\hline History of major depression & & & $<0.001$ \\
\hline No & 13057 (90.6) & 15304 (82.4) & \\
\hline Yes & $1419(9.4)$ & $3330(17.6)$ & \\
\hline $\begin{array}{l}\text { Frequency of alcohol } \\
\text { drinking }\end{array}$ & & & $<0.001$ \\
\hline Never & $5657(26.4)$ & 9806 (42.8) & \\
\hline Less than monthly & $1531(10.2)$ & 4331 (21.9) & \\
\hline Monthly & $1125(7.9)$ & $1978(10.6)$ & \\
\hline 2-4 times/mo & $3423(25.0)$ & $2960(16.5)$ & \\
\hline 2-3 times/wk & $3027(20.2)$ & $1146(6.3)$ & \\
\hline$\geq 4$ times/wk & $1835(10.3)$ & $359(1.9)$ & \\
\hline $\begin{array}{l}\text { Quantity of alcohol drinking } \\
\text { per occasion (drinks) }\end{array}$ & & & $<0.001$ \\
\hline 0 & 5627 (26.3) & 9772 (42.6) & \\
\hline $1-2$ & 2018 (11.1) & $5892(28.7)$ & \\
\hline $3-4$ & 2218 (13.2) & $2612(14.3)$ & \\
\hline $5-6$ & 2098 (14.6) & $1211(7.3)$ & \\
\hline $7-9$ & 2186 (15.8) & $608(3.7)$ & \\
\hline$\geq 10$ & $2448(19.0)$ & 495 (3.5) & \\
\hline Categorized AUDIT scores & & & $<0.001$ \\
\hline $0-7$ & $11705(59.2)$ & 20079 (89.1) & \\
\hline $8-15$ & $3744(24.3)$ & $1485(8.4)$ & \\
\hline $16-19$ & $1306(8.3)$ & $216(1.1)$ & \\
\hline$\geq 20$ & $1308(8.2)$ & $220(1.4)$ & \\
\hline $\begin{array}{l}\text { Frequency of alcoholic } \\
\text { blackouts }\end{array}$ & & & $<0.001$ \\
\hline Never & $12210(73.2)$ & 18749 (91.7) & \\
\hline Less than monthly & $2205(15.8)$ & $911(5.7)$ & \\
\hline Monthly & $1132(8.1)$ & $294(1.9)$ & \\
\hline More than once a week & $440(2.9)$ & $105(0.7)$ & $<0.001$ \\
\hline \multicolumn{4}{|l|}{ Suicidal ideation } \\
\hline Ever & $1613(10.2)$ & $3908(20.5)$ & \\
\hline Never & 12855 (89.8) & 14719 (79.5) & \\
\hline Suicide attempt & & & $<0.001$ \\
\hline Ever & $116(0.6)$ & $206(1.0)$ & \\
\hline Never & 16510 (99.4) & 20389 (99.0) & \\
\hline
\end{tabular}

Values are presented as number (\%).

AUDIT, Alcohol Use Disorders Identification Test.

${ }^{1}$ Megalopolis characterizes those living in Seoul.

${ }^{2}$ Metropolitan refers to those living in other large cities. 
Table 2. Characteristics affecting suicidal ideation and suicide attempts by sex

\begin{tabular}{|c|c|c|c|c|c|c|c|c|}
\hline & \multicolumn{4}{|c|}{ Male } & \multicolumn{4}{|c|}{ Female } \\
\hline & \multicolumn{2}{|c|}{ Suicidal ideation } & \multicolumn{2}{|c|}{ Suicide attempt } & \multicolumn{2}{|c|}{ Suicidal ideation } & \multicolumn{2}{|c|}{ Suicide attempt } \\
\hline & Never & Ever & Never & Ever & Never & Ever & Never & Ever \\
\hline$<40$ & 5381 (91.5) & $514(8.5)$ & 8009 (99.6) & $27(0.4)$ & $5980(82.1)$ & $1248(17.9)$ & 9136 (99.1) & $67(0.9)$ \\
\hline $40-64$ & 5147 (89.2) & $623(10.8)$ & 5732 (99.2) & $48(0.8)$ & $6102(81.5)$ & $1380(18.5)$ & 7400 (98.9) & $74(1.1)$ \\
\hline \multicolumn{9}{|c|}{ No. of household members } \\
\hline $1-2$ & 3392 (87.6) & $558(12.4)$ & 3936 (98.8) & $47(1.2)$ & 4032 (73.2) & $1475(26.8)$ & 5451 (98.6) & $72(1.4)$ \\
\hline 3 & 3033 (89.6) & $365(10.4)$ & 3696 (99.4) & $27(0.6)$ & 3235 (79.1) & 833 (20.9) & $4344(99.1)$ & $37(0.9)$ \\
\hline 4 & 4278 (90.8) & 453 (9.2) & 5847 (99.6) & $26(0.4)$ & 4654 (83.0) & $957(17.0)$ & 6554 (99.1) & $58(0.9)$ \\
\hline Middle school & 1965 (88.2) & $267(11.8)$ & 2201 (98.7) & $30(1.3)$ & 1894 (78.7) & 478 (21.3) & 2340 (98.6) & $25(1.4)$ \\
\hline High school & $4206(90.7)$ & $439(9.3)$ & 4624 (99.5) & $24(0.5)$ & $4583(82.5)$ & $936(17.5)$ & 5460 (98.9) & $54(1.1)$ \\
\hline$\geq$ College & 3755 (92.9) & $289(7.1)$ & 4036 (99.8) & $8(0.2)$ & 3475 (86.4) & $536(13.6)$ & 3994 (99.7) & $16(0.3)$ \\
\hline$p$-value & \multicolumn{2}{|c|}{$<0.001$} & \multicolumn{2}{|c|}{$<0.001$} & \multicolumn{2}{|c|}{$<0.001$} & \multicolumn{2}{|c|}{$<0.001$} \\
\hline Household income level & & & & & & & & \\
\hline Low & 2092 (83.3) & $492(16.7)$ & $2716(98.4)$ & $51(1.6)$ & $2673(68.6)$ & $1225(31.4)$ & 3968 (97.9) & $84(2.1)$ \\
\hline Mid-low & 3129 (88.9) & $419(11.1)$ & 4188 (99.5) & $20(0.5)$ & 3580 (78.3) & $1027(21.7)$ & 5146 (98.8) & $56(1.2)$ \\
\hline Mid-high & 3681 (91.8) & $338(8.2)$ & 4696 (99.6) & $20(0.4)$ & 4039 (82.7) & 864 (17.3) & 5575 (99.3) & $42(0.7)$ \\
\hline High & 3729 (91.9) & $329(8.1)$ & 4637 (99.6) & $20(0.4)$ & 4161 (85.4) & $692(14.6)$ & 5313 (99.5) & $19(0.5)$ \\
\hline Employment state & & & & & & & & \\
\hline Employed & 8460 (91.2) & 877 (8.8) & 9289 (99.5) & $54(0.5)$ & 6422 (81.5) & $1500(18.5)$ & 7842 (99.0) & $70(1.0)$ \\
\hline Unemployed & 3027 (86.0) & $545(14.0)$ & 3519 (98.8) & $54(1.2)$ & $6739(78.1)$ & $1962(21.9)$ & 8594 (98.8) & $107(1.2)$ \\
\hline$p$-value & $<0$ & & & & & .001 & & \\
\hline Lives with spouse & & & & & & & & \\
\hline Yes & 8792 (90.4) & $1039(9.6)$ & 9781 (99.4) & $67(0.6)$ & 9468 (82.4) & 2131 (17.6) & 11485 (99.1) & $101(0.9)$ \\
\hline No & 3337 (88.4) & $509(11.6)$ & 5337 (99.3) & $44(0.7)$ & $4629(74.0)$ & $1645(26.0)$ & 7595 (98.7) & $95(1.3)$ \\
\hline$p$-value & 0.0 & & & & & .001 & & \\
\hline Private insurance & & & & & & & & \\
\hline Yes & 8853 (91.3) & $858(8.7)$ & 11565 (99.6) & $54(0.4)$ & 10488 (82.9) & 2157 (17.1) & 14273 (99.3) & $98(0.7)$ \\
\hline No & $3740(85.4)$ & $726(14.6)$ & 4622 (98.9) & $60(1.1)$ & 3974 (70.4) & $1684(29.6)$ & $5760(98.0)$ & $104(2.0)$ \\
\hline$p$-value & $<0$ & & & & & .001 & & \\
\hline Smoking status & & & & & & & & \\
\hline Non & 3243 (92.6) & $306(7.4)$ & 5683 (99.6) & $24(0.4)$ & 12921 (81.2) & 3142 (18.8) & 17894 (99.2) & $138(0.8)$ \\
\hline Ex-smoker & $1902(90.7)$ & $209(9.3)$ & 2096 (99.5) & $15(0.5)$ & $300(73.2)$ & $104(26.8)$ & $396(97.9)$ & $8(2.1)$ \\
\hline Current smoker & 7146 (88.6) & 1018 (11.4) & 8092 (99.3) & $72(0.7)$ & $1040(67.0)$ & 553 (33.0) & 1536 (96.5) & $55(3.5)$ \\
\hline$p$-value & $<0$ & & & & & .001 & & \\
\hline
\end{tabular}


Table 2. Continued from the previous page

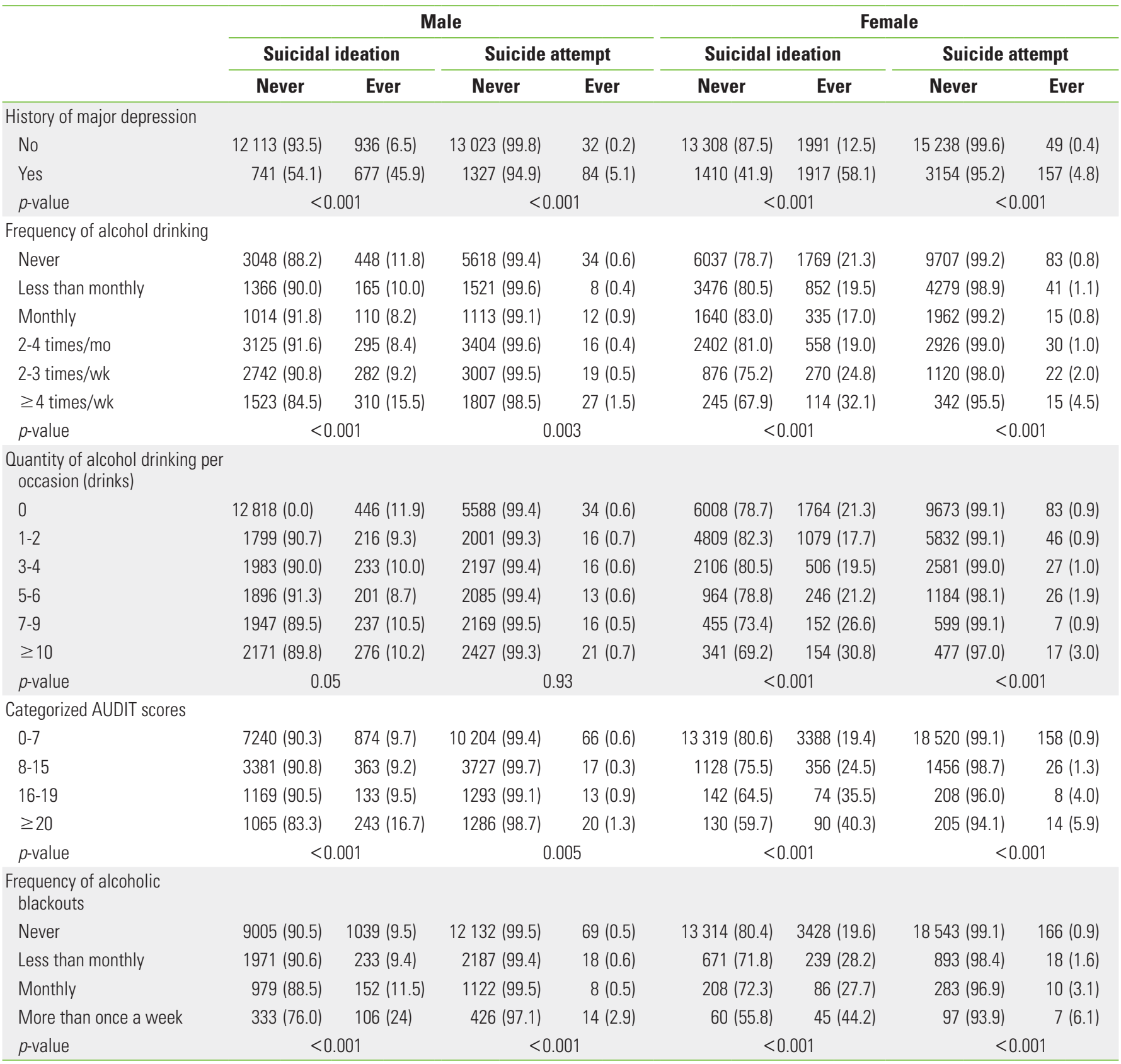

Values are presented as number (\%).

AUDIT, Alcohol Use Disorders Identification Test.

${ }^{1}$ Megalopolis characterizes those living in Seoul.

${ }^{2}$ Metropolitan refers to those living in other large cities.

males and females for most sociodemographic factors and alcohol consumption patterns. Among the study subjects, 1613 males (10.2\%) and 3908 females (20.5\%) reported that they had experienced suicidal ideation in the previous 12 months, and 116 males (0.6\%) and 206 females (1.0\%) had attempted suicide during the previous 12 months.

The sociodemographic characteristics affecting suicidal ide- ation and suicide attempts are shown in Table 2 . The prevalence of suicidal ideation and suicide attempts decreased as education level and household income level increased. The prevalence of suicidal ideation was greater among participants living in rural areas, but this tendency was not statistically significant in suicide attempters. The prevalence of suicidal ideation and suicide attempts was greater among those who were 
unemployed, living alone, or who had no private insurance. Differences in suicidal ideation were found depending on smoking status, but smoking status had no association with suicide attempts. Significant differences were found depending on whether a history of major depression was present, with a greater prevalence of both suicidal ideation and suicide attempts, among those with a history of major depression.

The prevalence of suicidal ideation and suicide attempts in females was higher than in males. As the level of education and household income increased, the prevalence of suicidal behavior decreased. The effects of characteristics involving region of residence, employment status, living alone, and private insurance were similar to those found in males. However, the prevalence of suicide attempts by smoking status increased from non-smokers to ex-smokers and current smokers. The effect of a history of major depression was similar to that found in males.

Table 3 shows the results of all adjusted logistic regression analyses between patterns of alcohol consumption and suicidal behavior. We display the associations of the four types of alcohol consumption patterns that were analyzed (drinking frequency, drinking quantity, frequency of alcoholic blackouts, and categorized AUDIT score) with suicidal ideation and suicide attempts in males and females.

In males, no significant associations were found between either drinking frequency or drinking quantity and suicidal be-

Table 3. Logistic regression results regarding the associations of patterns of alcohol consumption with suicidal ideation and suicide attempts by sex

\begin{tabular}{|c|c|c|c|c|c|c|c|c|}
\hline & \multicolumn{4}{|c|}{ Male } & \multicolumn{4}{|c|}{ Female } \\
\hline & \multicolumn{2}{|c|}{ Suicidal ideation } & \multicolumn{2}{|c|}{ Suicide attempts } & \multicolumn{2}{|c|}{ Suicidal ideation } & \multicolumn{2}{|c|}{ Suicide attempts } \\
\hline & OR $(95 \% \mathrm{CI})$ & $p$ for trend & OR $(95 \% \mathrm{CI})$ & $p$ for trend & OR (95\% CI) & $p$ for trend & OR (95\% CI) & $p$ for trend \\
\hline Never & 1.00 (reference) & & 1.00 (reference) & & 1.00 (reference) & & 1.00 (reference) & \\
\hline 2-4 times/mo & $0.87(0.65,1.18)$ & & $0.87(0.35,2.18)$ & & $1.13(0.95,1.34)$ & & $1.16(0.61,2.22)$ & \\
\hline 2-3 times/wk & $0.88(0.65,1.20)$ & & $0.84(0.39,1.80)$ & & $1.41(1.11,1.80)$ & & $1.26(0.58,2.75)$ & \\
\hline$\geq 4$ times/wk & $1.22(0.91,1.64)$ & & $1.26(0.63,2.52)$ & & $1.57(1.12,2.20)$ & & $2.85(1.18,6.87)$ & \\
\hline $\begin{array}{l}\text { Quantity of alcohol drinking } \\
\text { per occasion (drinks) }\end{array}$ & & 0.05 & & 0.08 & & $<0.001$ & & 0.18 \\
\hline $5-6$ & $0.88(0.64,1.21)$ & & $1.04(0.40,2.74)$ & & $1.27(1.01,1.59)$ & & $2.24(1.13,4.41)$ & \\
\hline $7-9$ & $1.10(0.80,1.50)$ & & $0.89(0.41,1.95)$ & & $1.51(1.14,2.00)$ & & $0.51(0.18,1.48)$ & \\
\hline$\geq 10$ & $1.02(0.74,1.40)$ & & $1.07(0.49,2.36)$ & & $1.84(1.28,2.65)$ & & $1.92(0.80,4.60)$ & \\
\hline $\begin{array}{l}\text { Frequency of alcoholic } \\
\text { blackouts }\end{array}$ & & $<0.001$ & & 0.17 & & $<0.001$ & & 0.06 \\
\hline Never & 1.00 (reference) & & 1.00 (reference) & & 1.00 (reference) & & 1.00 (reference) & \\
\hline Less than monthly & $1.13(0.91,1.41)$ & & $0.87(0.43,1.78)$ & & $1.63(1.29,2.07)$ & & $1.19(0.60,2.38)$ & \\
\hline Monthly & $1.17(0.90,1.52)$ & & $0.64(0.26,1.57)$ & & $1.42(0.99,2.05)$ & & $1.76(0.71,4.40)$ & \\
\hline More than once a week & $2.14(1.47,3.13)$ & & $2.37(1.14,4.94)$ & & $2.16(1.20,3.89)$ & & $2.51(0.82,7.65)$ & \\
\hline
\end{tabular}

Adjusted for age, number of household member, education level, household income level, region, employment status, living alone, private insurance, smoking status, and history of major depression.

OR, odds ratio; Cl, confidence interval; AUDIT, Alcohol Use Disorders Identification Test. 
havior. A greater than weekly frequency of alcoholic blackouts was associated with an OR for suicidal ideation of 2.14 (95\% $\mathrm{Cl}, 1.47$ to 3.13 ), and AUDIT scores of 20 and over were associated with an OR for suicidal ideation of $1.68(95 \% \mathrm{Cl}, 1.28$ to 2.10). The trend tests for suicidal ideation were statistically significant depending on the frequency of alcoholic blackouts and AUDIT scores. A greater than weekly frequency of alcoholic blackouts was associated with an OR for suicide attempt of $2.37(95 \% \mathrm{Cl}, 1.14$ to 4.94$)$, but the trend was not significant.

A drinking frequency of two to three times per week was associated with an OR for suicidal ideation of $1.41(95 \% \mathrm{Cl}, 1.11$ to 1.80 ), and a drinking frequency of more than four times per week was associated with an OR for suicidal ideation of 1.57 ( $95 \% \mathrm{Cl}, 1.12$ to 2.20 ). The consumption of three or more drinks per occasion was associated with suicidal ideation, that were significantly higher than what was observed for nondrinkers. A greater than weekly frequency of alcoholic blackouts was associated with an OR for suicidal ideation of 2.16 ( $95 \% \mathrm{Cl}, 1.20$ to 3.89). Higher AUDIT scores were associated with a significantly increased OR for suicidal ideation. The trends of suicidal ideation were found to be statistically significant for all patterns of alcohol consumption that were analyzed. A drinking frequency of four times per week or more was associated with an OR for suicide attempts of $2.85(95 \% \mathrm{Cl}, 1.18$ to 6.87), and AUDIT scores of 20 and over were associated with an OR for suicide attempts of 2.64 ( $95 \% \mathrm{Cl}, 1.17$ to 5.96$)$.

\section{DISCUSSION}

According to the 2007-2011 KNHANES results, $10.2 \%$ of males and $20.5 \%$ of females have experienced suicidal ideation, and $0.6 \%$ of males and $1.0 \%$ of females attempt suicide each year in Korea. According to data from Statistics Korea, the suicide rate in Korea was 31.7 per 100000 people, making suicide the fourth leading cause of death in 2011 [19]. In the US, the 12-month prevalence estimate of suicide attempts was $0.4 \%$, according to the National Comorbidity Survey, and the suicide rate was approximately 11.0 per 100000 [18]. Considering that the mean suicide rate of OECD countries has been lower than 15 per 100000 people since 2000 [20], suicide is clearly a major public health problem in Korea.

Numerous factors influence suicidal ideation and suicide attempts. Social factors such as economic deprivation, poor educational attainment, unemployment, or the death of a spouse are related to suicide and physical illnesses like cancer, AIDS, di- abetes, schizophrenia, and alcohol use disorders. Previous studies have shown that a history of major depression and high emotional stress increase the risk of suicide attempts [4,21-25]. Korea is engaged in several suicide prevention campaigns, but they have not yet shown clear effects.

One of the neurobiological mechanisms associated with suicide is an abnormal serotonergic reaction, as indicated by features such as increased serotonin receptors and decreased serotonin metabolites (e.g., 5-hydroxyindoleacetic acid) [26]. It is well known that chronic alcohol exposure is linked to the action of serotonin, and that alcohol suppresses functional changes in serotonin [27].

We found that AUDIT scores were associated with suicidal ideation in males and associated with suicidal ideation and suicide attempts in females. Especially in females, higher AUDIT scores were associated with significantly higher ORs for suicidal ideation than were found with AUDIT scores of 7 and lower, and a tendency was noted for increased ORs for suicidal ideation to correlate with increased AUDIT scores. McCloud et al. [28] found that AUDIT scores were associated with suicidal behavior in a psychiatric population. Their results were similar to ours, but they did not find a sex difference. Their study subjects were limited to psychiatric patients, which could have affected their results. We were unable to find any study evaluating these associations in the general adult population. Thus, to our knowledge, this is the first study to examine the association between AUDIT scores and suicidal behavior in the general adult population.

Alcoholic blackouts were associated with suicidal ideation and suicide attempts in males, and were associated with suicidal ideation in females. In males, a frequency of alcoholic blackouts of more than once a week was associated with a significantly higher OR for suicidal ideation and suicide attempts. In females, a non-zero frequency of alcoholic blackouts was associated with suicidal ideation ORs higher than that found among those who had never experienced alcoholic blackouts, but a monthly frequency of blackouts was not found to have a significant effect. To the best of our knowledge, this is the first study to examine the association between alcoholic blackouts and suicidal behavior.

In this study, patterns of alcohol consumption and suicidal behavior were found to be different among males and females. Previous studies have shown that patterns of alcohol consumption and emergence of drinking problem were different be sex, and they were associated with the weight of body water $[29,30]$. It is also known that the risk factors of suicide differ ac- 
cording to sex [31,32]. In a study conducted on middle-aged adults in Korea, risk factors relating to suicide in males were associated with marital status, while risk factors relating to suicide among females were associated with type of occupation and income [33].

This study has some limitations. These results are not able to address the causality of alcoholic behavior and suicidal behavior because we used cross-sectional data. The problem of reverse causation is most likely derived from depression. Alcohol abuse can lead to depression, causing suicide, while patients with depression may use alcohol to alleviate depression [20]. However, we controlled for major depression, which refers to a depressive state lasting more than two weeks during the previous 12 months. Furthermore, most of the data were self-reported, so recall bias may also be a factor. Additionally, selection bias may be present due to the rejection of some responses in the formulation of the KNHANES. Although the rate of suicide attempts is high in adolescence [34], we were unable to examine this age range due to limitations of the survey data. However, the study population of previous studies about alcohol use and suicide attempts included only alcohol-dependent individuals. One advantage of this study is that we used data from a nationwide survey. Another advantage is that this is the first study to compare the strength of associations between four types of behavior regarding alcohol consumption and suicidal behavior.

Suicide is an important public health problem in Korea. In this study we found that distinct patterns of alcohol consumption were associated with suicidal behaviors. In particular, only alcoholic blackouts and categorized AUDIT scores were associated with suicidal behavior in males. We therefore suggest that further research is needed to examine this relationship prospectively and in other settings.

\section{CONFLICT OF INTEREST}

The authors have no conflicts of interest related to the material presented in this paper.

\section{REFERENCES}

1. Statistics Korea. Annual report on the cause of death statistics [cited 2013 Jun 6]. Available from: http://kostat.go.kr (Korean).

2. Organisation for Economic Cooperation and Development. OECD factbook 2013: economic, environmental and social sta- tistics [cited 2013 Jan 9]. Available from: http://www.oecd-ilibrary.org/economics/oecd-factbook-2013_factbook-2013-en.

3. Preuss UW, Schuckit MA, Smith TL, Danko GP, Bucholz KK, Hesselbrock MN, et al. Predictors and correlates of suicide attempts over 5 years in 1,237 alcohol-dependent men and women. Am J Psychiatry 2003;160(1):56-63.

4. Suokas J, Suominen K, Isometsä E, Ostamo A, Lönnqvist J. Longterm risk factors for suicide mortality after attempted suicide-findings of a 14-year follow-up study. Acta Psychiatr Scand 2001;104(2):117-121.

5. Foster T, Gillespie K, McClelland R, Patterson C. Risk factors for suicide independent of DSM-III-R Axis I disorder. Case-control psychological autopsy study in Northern Ireland. Br J Psychiatry 1999;175:175-179.

6. Johnsson Fridell E, Ojehagen A, Träskman-Bendz L. A 5-year follow-up study of suicide attempts. Acta Psychiatr Scand 1996; 93(3):151-157.

7. Schmidtke A, Bille-Brahe U, DeLeo D, Kerkhof A, Bjerke T, Crepet $P$, et al. Attempted suicide in Europe: rates, trends and sociodemographic characteristics of suicide attempters during the period 1989-1992. Results of the WHO/EURO Multicentre Study on Parasuicide. Acta Psychiatr Scand 1996;93(5): 327-338.

8. Ezzati M, Lopez AD, Rodgers A, Vander Hoorn S, Murray CJ; Comparative Risk Assessment Collaborating Group. Selected major risk factors and global and regional burden of disease. Lancet 2002;360(9343):1347-1360.

9. Kendall RE. Alcohol and suicide. Subst Alcohol Actions Misuse 1983;4(2-3):121-127.

10. Boenisch S, Bramesfeld A, Mergl R, Havers I, Althaus D, Lehfeld $\mathrm{H}$, et al. The role of alcohol use disorder and alcohol consumption in suicide attempts--a secondary analysis of 1921 suicide attempts. Eur Psychiatry 2010;25(7):414-420.

11. Buri C, von Bonin B, Strik W, Moggi F. Predictors of attempted suicide among Swiss patients with alcohol-use disorders. J Stud Alcohol Drugs 2009;70(5):668-674.

12. Modesto-Lowe V, Brooks D, Ghani M. Alcohol dependence and suicidal behavior: from research to clinical challenges. Harv Rev Psychiatry 2006;14(5):241-248.

13. Babor TF, Higgins-Biddle JC, Saunders JB, Monteiro MG. AUDIT : the alcohol use disorders identification test: guidelines for use in primary care. Geneva: World Health Organization; 2001, p.19-20.

14. Lee H, Roh S, Kim DJ. Alcohol-induced blackout. Int J Environ Res Public Health 2009;6(11):2783-2792. 
15. Vignau J, Soichot $M$, Imbenotte $M$, Jacquemont MC, Danel $T$, Vandamme $M$, et al. Impact of tryptophan metabolism on the vulnerability to alcohol-related blackouts and violent impulsive behaviours. Alcohol Alcohol 2010;45(1):79-88.

16. Sibthorpe B, Drinkwater J, Gardner K, Bammer G. Drug use, binge drinking and attempted suicide among homeless and potentially homeless youth. Aust N Z J Psychiatry 1995;29(2): 248-256.

17. Mukamal KJ, Kawachi I, Miller M, Rimm EB. Drinking frequency and quantity and risk of suicide among men. Soc Psychiatry Psychiatr Epidemiol 2007;42(2):153-160.

18. Centers for Disease Control and Prevention. Web-based Injury Statistics Query and Reporting System(WISQARS) [cited 2011 July 11]. Available from: http://www.cdc.gov/injury/wisqars/ index.html.

19. Boccolini Pde M, Boccolini CS, Chrisman Jde R, Markowitz SB, Koifman S, Koifman RJ, et al. Pesticide use and non-Hodgkin's lymphoma mortality in Brazil. Int J Hyg Environ Health 2013; 216(4):461-466.

20. Alavanja MC, Ross MK, Bonner MR. Increased cancer burden among pesticide applicators and others due to pesticide exposure. CA Cancer J Clin 2013;63(2):120-142.

21. Hiroeh U, Appleby L, Mortensen PB, Dunn G. Death by homicide, suicide, and other unnatural causes in people with mental illness: a population-based study. Lancet 2001;358(9299): 2110-2112.

22. Mortensen PB, Agerbo E, Erikson T, Qin P, Westergaard-Nielsen N. Psychiatric illness and risk factors for suicide in Denmark. Lancet 2000;355(9197):9-12.

23. Kessler RC, Borges G, Walters EE. Prevalence of and risk factors for lifetime suicide attempts in the National Comorbidity Survey. Arch Gen Psychiatry 1999;56(7):617-626.
24. Mościcki EK. Epidemiology of suicide. Int Psychogeriatr 1995; 7(2):137-148.

25. Blumenthal SJ. Suicide: a guide to risk factors, assessment, and treatment of suicidal patients. Med Clin North Am 1988; 72(4):937-971.

26. Pandey GN. Biological basis of suicide and suicidal behavior. Bipolar Disord 2013;15(5):524-541.

27. Lovinger DM. Serotonin's role in alcohol's effects on the brain. Alcohol Health Res World 1997;21(2):114-120.

28. McCloud A, Barnaby B, Omu N, Drummond C, Aboud A. Relationship between alcohol use disorders and suicidality in a psychiatric population: in-patient prevalence study. Br J Psychiatry 2004;184:439-445.

29. Mumenthaler MS, Taylor JL, O'Hara R, Yesavage JA. Gender differences in moderate drinking effects. Alcohol Res Health 1999;23(1):55-64.

30. Nolen-Hoeksema S. Gender differences in risk factors and consequences for alcohol use and problems. Clin Psychol Rev 2004;24(8):981-1010.

31. Lee HY, Hahm MI, Park EC. Differential association of socioeconomic status with gender- and age-defined suicidal ideation among adult and elderly individuals in South Korea. Psychiatry Res 2013;210(1):323-328.

32. Qin P, Agerbo E, Westergård-Nielsen N, Eriksson T, Mortensen PB. Gender differences in risk factors for suicide in Denmark. Br J Psychiatry 2000;177:546-550.

33. Moon SS, Park SM. Risk factors for suicidal ideation in Korean middle-aged adults: the role of socio-demographic status. Int J Soc Psychiatry 2012;58(6):657-663.

34. Fremouw W, Callahan T, Kashden J. Adolescent suicidal risk: psychological, problem solving, and environmental factors. Suicide Life Threat Behav 1993;23(1):46-54. 